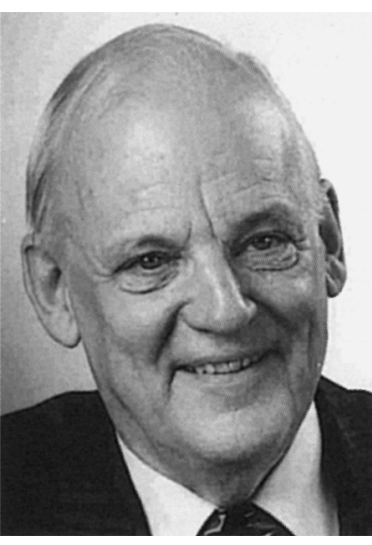

Gösta Samuelson gosta.samuelson@htu.se

\title{
Obesity in the young: a risk for type 2 diabetes
}

$\mathrm{I}$ $\mathrm{n}$ the USA, Japan and Australia an increasing incidence of type 2 diabetes in overweight and obese children and young people is reported. Previously, type 2 diabetes was usually called "non-insulin-dependent diabetes" and appeared in middle-aged and elderly people, but nowadays it is also increasingly being diagnosed in young age groups. In the European countries only scarce population-based incidence and prevalence data exist, as reported by Éva Erhardt and Dénes Molnár in a review article in this issue of the Scandinavian Journal of Nutrition (SJN). The existing prevalence figures of type 2 diabetes in the young are still very low compared with the prevalence of type 1 diabetes in children aged under 18 years. However, referring to different European studies of obese children, the prevalence of type 2 diabetes varies between 0.1 and $1.9 \%$ and that of impaired glucose tolerance (IGT) between 4.5 and 18\%. A screening programme for individuals at risk is suggested.

\section{Impaired glucose tolerance and obesity}

IGT is prevalent among US children and adolescents with marked obesity, R. Sinha et al. conclude in a study published in the New England Journal of Medicine (2002;346:802-10). In highly obese children, $25 \%$ of those aged between 4 and 10 years and $21 \%$ between 11 and 18 years had impaired glucose intolerance associated with insulin resistance. These figures are higher than the European ones referred to in the above-cited review. Two conclusions may be drawn from these and other similar studies. First, an oral glucose tolerance test should be performed in all markedly obese children and adolescents for the early detection of IGT and silent type 2 diabetes, with the aim of starting early treatment. Secondly, a preventive strategy focusing on diet and physical activity for a healthy lifestyle is of the highest priority.

\section{Cultural aspects of meal patterns}

In a series on meal patterns, Christina Fjellström describes historical and ethnological aspects of the development of eating habits in Sweden. It is of great interest to analyse the background to changes in society over the years and the impact of these changes on food habits and meal composition. Cultural and social aspects of meals and eating in all age groups are an important research field, particularly in our modern society where people often eat outside the home and family, and often alone, without social interaction.

\section{New Nordic Nutrition Recommendations (NNR)}

The 4th edition of the NNR 2004 was approved by the Nordic Council of Ministers in August 2004. The work was done by a Nordic group of scientists, chaired by Wulf Becker. A shortened version is given in this issue of SJN. The major change from the 3rd Edition (1996) is the inclusion of recommendations on daily physical activity, and the interaction between energy and nutrient intakes and physical activity. This approach is most welcome. New reference values for energy intakes in groups of infants and small children, as well as for adults, are given. The intake of saturated fat and trans fatty acids is limited to about $10 \mathrm{E} \%$, and total daily fat intake to $30 \mathrm{E} \%$. For children the $E^{\%} \%$ from fat should be reduced from high levels during the first year of life to the same level as for adults from the age of 2 years. An increased intake of carbohydrate and fibre is recommended, while the intake of refined sugar should not exceed $10 \mathrm{E} \%$. Recommendations of dietary intakes of certain vitamins have been changed. It should be kept in mind that the recommendations are based on the present nutritional situation in the Nordic countries and should be used for planning and evaluation of diets for groups of healthy subjects. 